\title{
Chloroquine Interference with Hemoglobin Endocytic Trafficking Suppresses Adaptive Heme and Iron Homeostasis in Macrophages: The Paradox of an Antimalarial Agent
}

\author{
Christian A. Schaer, ${ }^{1}$ Endre Laczko, ${ }^{2}$ Gabriele Schoedon, ${ }^{3}$ \\ Dominik J. Schaer, ${ }^{3}$ and Florence Vallelian ${ }^{3}$ \\ ${ }^{1}$ Department of Anesthesiology, University Hospital, 8091 Zurich, Switzerland \\ ${ }^{2}$ Functional Genomics Center, University of Zurich, 8057 Zurich, Switzerland \\ ${ }^{3}$ Division of Internal Medicine, University Hospital, 8091 Zurich, Switzerland \\ Correspondence should be addressed to Florence Vallelian; florence.vallelian@usz.ch
}

Received 28 February 2013; Accepted 12 April 2013

Academic Editor: Emanuela Tolosano

Copyright ( 2013 Christian A. Schaer et al. This is an open access article distributed under the Creative Commons Attribution License, which permits unrestricted use, distribution, and reproduction in any medium, provided the original work is properly cited.

\begin{abstract}
The CD163 scavenger receptor pathway for $\mathrm{Hb}: \mathrm{Hp}$ complexes is an essential mechanism of protection against the toxicity of extracellular hemoglobin $(\mathrm{Hb})$, which can accumulate in the vasculature and within tissues during hemolysis. Chloroquine is a lysosomotropic agent, which has been extensively used as an antimalarial drug in the past, before parasite resistance started to limit its efficacy in most parts of the world. More recent use of chloroquine is related to its immunomodulatory activity in patients with autoimmune diseases, which may also involve hemolytic disease components. In this study we examined the effects of chloroquine on the human $\mathrm{Hb}$ clearance pathway. For this purpose we developed a new mass-spectrometry-based method to specifically quantify intracellular $\mathrm{Hb}$ peptides within the endosomal-lysosomal compartment by single reaction monitoring (SRM). We found that chloroquine exposure impairs trafficking of $\mathrm{Hb}: \mathrm{Hp}$ complexes through the endosomal-lysosomal compartment after internalization by CD163. Relative quantification of intracellular $\mathrm{Hb}$ peptides by SRM confirmed that chloroquine blocked cellular $\mathrm{Hb}: \mathrm{Hp}$ catabolism. This effect suppressed the cellular heme-oxygenase-1 (HO-1) response and shifted macrophage iron homeostasis towards inappropriately high expression of the transferrin receptor with concurrent inhibition of ferroportin expression. A functional deficiency of $\mathrm{Hb}$ detoxification and heme-iron recycling may therefore be an adverse consequence of chloroquine treatment during hemolysis.
\end{abstract}

\section{Introduction}

Extracellular hemoglobin $(\mathrm{Hb})$ is the pathophysiologic consequence of hemolysis and is not innocuous [1]. The injurious impact of free $\mathrm{Hb}$ has been ascribed to heme-driven oxidative processes and vascular dysfunction. A functionally intact clearance pathway is thus essential for rapid and efficient elimination and detoxification of free $\mathrm{Hb}$ and prevention of its deleterious effects $[2,3]$.

The $\mathrm{CD} 163$ receptor facilitates endocytosis of free $\mathrm{Hb}$ and $\mathrm{Hb}$-haptoglobin ( $\mathrm{Hb}: \mathrm{Hp}$ ) complexes for intralysosomal processing by blood monocytes and resident tissue macrophages, primarily in the liver and spleen [4-6]. When eventually delivered to the cytoplasm, the globin-free heme is degraded by heme-oxygenase-1 (HO-1) [7, 8]. A diminished pool of monocytes/macrophages, as well as any loss of lysosomal function or lack of HO-1 activity, may therefore compromise physiologic $\mathrm{Hb}$ detoxification, increasing the likelihood of pathology $[9,10]$.

Chloroquine is a lysosomotropic weak base and accumulates within acidic cellular compartments. The pharmacologic action of chloroquine includes an increase in intralysosomal $\mathrm{pH}$, preventing fusion of endosomes and lysosomes, and, consequently, disruption of intracellular trafficking [11-13]. Historically, this agent was widely used for the treatment of malaria-a prototypic hemolytic condition. The efficacy of 
chloroquine as an antimalarial drug is owed to inhibition of heme catabolism in plasmodium parasites. By blocking polymerization of $\mathrm{Hb}$-derived ferriprotoporphyrin IX, highly toxic heme-chloroquine complexes accumulate, thus limiting parasite survival [14]. In contrast, preserving the $\mathrm{Hb}$ clearance pathway in malaria infected patients is critical. Oxidative heme toxicity to the blood-brain barrier has been intimately linked to some of the most severe cerebral complications of this disease [15], and efficient Hb-iron recycling is critical to support erythropoiesis during severe anemia, which is one of the major worldwide causes of malaria death [16-18]. It is so far not known whether chloroquine could impair the $\mathrm{Hb}$ clearance pathway of human macrophages.

Although chloroquine has been largely abandoned as an antimalarial agent due to widespread emergence of resistant parasitic strains and availability of alternative medications $[19,20]$, clinical interest was regained in recent years, based on its utility as an effective immunomodulator. Chloroquine and its hydroxyl derivative, hydroxychloroquine, are now widely used as adjuncts in treatment of autoimmune diseases [21, 22]. However, hemolytic anemia is a notable and frequent manifestation in autoimmunity, such as in patients with systemic lupus erythematodes (SLEs). The potential drawbacks of chloroquine therapy, relative to impeded $\mathrm{Hb}$ detoxification, remain unknown and could overshadow the protective immunomodulatory benefits in some patients with a significant hemolytic disease component.

For the present study, we developed a new massspectrometry-based quantification method to track directly CD163 mediated uptake of Hb:Hp into lysosomes and subsequent decay processes. We found that chloroquine treatment resulted in intracellular $\mathrm{Hb}$ trapping, abolished $\mathrm{HO}-1$ expression, and suppression of the adaptive iron metabolism response. Our results suggest that chloroquine interferes with the hemoglobin scavenger pathway, potentially compromising efficient $\mathrm{Hb}$ clearance and aggravating ill effects of extracellular $\mathrm{Hb}$.

\section{Results}

2.1. Quantification of Internalized $\mathrm{Hb}$ Peptides Using Single Reaction Monitoring (SRM). We developed a proteintargeted single reaction monitoring (SRM) method for quantifying cell associated $\mathrm{Hb}$ by mass-spectrometry. The method is based on the sequence-specific identification and label-free quantification of paired peptide precursor- and fragment-ion masses, also known as transitions. Definitive transitions to be quantified were selected according to in silico peptide characteristics, inspection of relative peak intensities of different transitions, and retention time alignment of SRM signals. As such, we monitored three $\mathrm{Hb}$ peptides with at least three fragment ions per peptide. Optimal SRM signals were obtained for the following three $\mathrm{Hb}$ peptides: SAVTALWGK $(m / z$ 466.76), MFLSFPTTK $(m / z 536.27)$, and LLVVYPWTQR $(m / z$ 637.83).

In Figure 1, representative ion chromatograms of precursors and fragment ions are shown. Note that fragment ions of the same precursor peptide coelute at the same retention time. The relative precursor-ion quantity was calculated as the sum of the peak areas of all related fragment-ion chromatograms and was assumed to correlate with the respective $\mathrm{Hb}$ peptide quantity being present in the endosomallysosomal compartment.

\subsection{Chloroquine Promotes Intracellular $\mathrm{Hb}$ Accumulation.} Figure 2(a) shows representative CD163-transduced HEK293 cell pellets obtained after exposure of the cells to $\mathrm{Hb}: \mathrm{Hp}$ $(2 \mathrm{mg} / \mathrm{mL})$ for 12 hours. We have previously reported that the CD163-HEK-293 cell is a valuable model to study $\mathrm{Hb}$ endocytosis and subsequent cellular responses in vitro $[5,7]$. CD163-HEK-293 cells treated with chloroquine $(10 \mu \mathrm{M})$ $30 \mathrm{~min}$ before and during $\mathrm{Hb}: \mathrm{Hp}$ exposure clearly differed in appearance from control cells. The red-brown color of chloroquine-treated cells indicated greater accumulation of heme, as opposed to those not pretreated. This impression could be substantiated by spectrophotometric analysis of the lysed cell pellets which shows a significant $\mathrm{Hb}$ absorbance component in chloroquine-treated cells with characteristic absorbance peaks at $540 \mathrm{~nm}$ and $575 \mathrm{~nm}$ but much less than in control cells (insert in Figure 2(b)). In addition a significant absorption peak was detected at $630 \mathrm{~nm}$, which suggests that a fraction of $\mathrm{Hb}$ is oxidized to metHb $\left(\mathrm{Fe}^{3+}\right)$ after endocytosis within the acidic and proteolytic endolysosomal compartment (not shown). In Figure 2(b), the relative intensity profiles of SRM-trapped fragment ions is depicted for one representative $\mathrm{Hb}$ peptide. Compared with control samples, this analysis indicates a higher globin protein abundance in the $\mathrm{Hb}$ plus chloroquine-treated CD163-HEK-293 cell lysates compared to cells that were exposed to $\mathrm{Hb}$ in the absence of chloroquine. Collectively, the increased SRM signal in parallel to the brown appearance of the cell pellets confirms that not only heme but also the protein component (globin) of $\mathrm{Hb}$ massively accumulates in the chloroquine-treated cells.

2.3. Chloroquine Limits Intracellular $\mathrm{Hb}$ Clearance without Altering Cellular Uptake Capacity. We further addressed the question of whether chloroquine modifies CD163 mediated $\mathrm{Hb}$ uptake capacity or whether it interferes with the subsequent intracellular degradation pathway of $\mathrm{Hb}$. The fluorescence Hb:Hp uptake assay shown in Figure 3(a) shows that the uptake capacity of the chloroquine-treated cells within the first $30 \mathrm{~min}$ of incubation is equal to control cells, indicating that the accumulation of $\mathrm{Hb}$ observed in chloroquine-treated cells must be the result of a diminished $\mathrm{Hb}$ degradation, rather than increased $\mathrm{Hb}$ uptake. Figure 3(b) shows the SRM-determined decay of the endocytosed $\mathrm{Hb}$ peptides in chloroquine and control cell populations. After incubation with $\mathrm{Hb}: \mathrm{Hp}$ ( $2 \mathrm{mg} / \mathrm{mL}$ for 12 hours), the cells were washed with phosphate-buffered saline (PBS) containing EDTA to remove noninternalized $\mathrm{Hb}$. Cell samples were either lyzed immediately after washing (0-hour sample) or further incubated at $37^{\circ} \mathrm{C}$ and lysed after 180 minutes to quantify intracellular $\mathrm{Hb}$ peptides relative to the 0 -hour samples. While we observed a considerable decrease of $\mathrm{Hb}$ peptides in control cells, $\mathrm{Hb}$ elimination was blocked by chloroquine treatment. Therefore, our results suggest that 


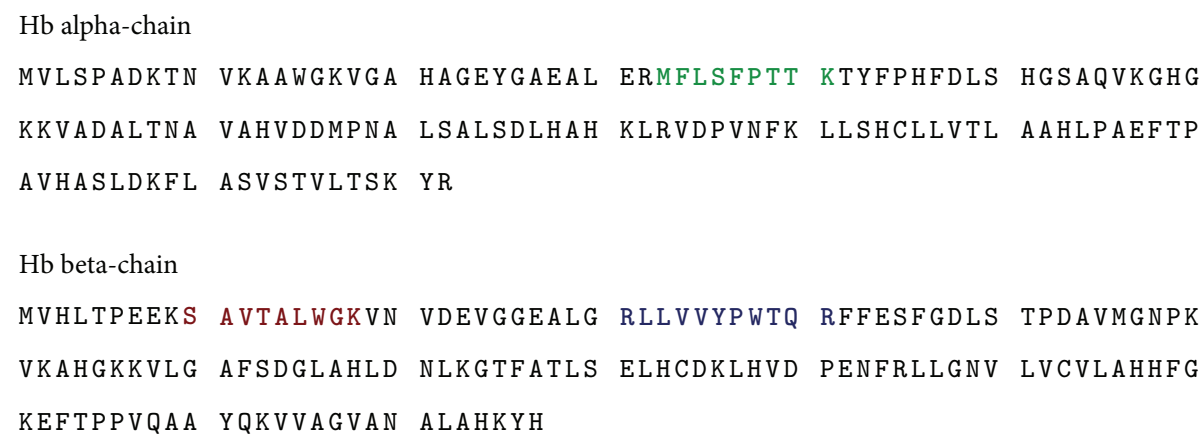

(a)

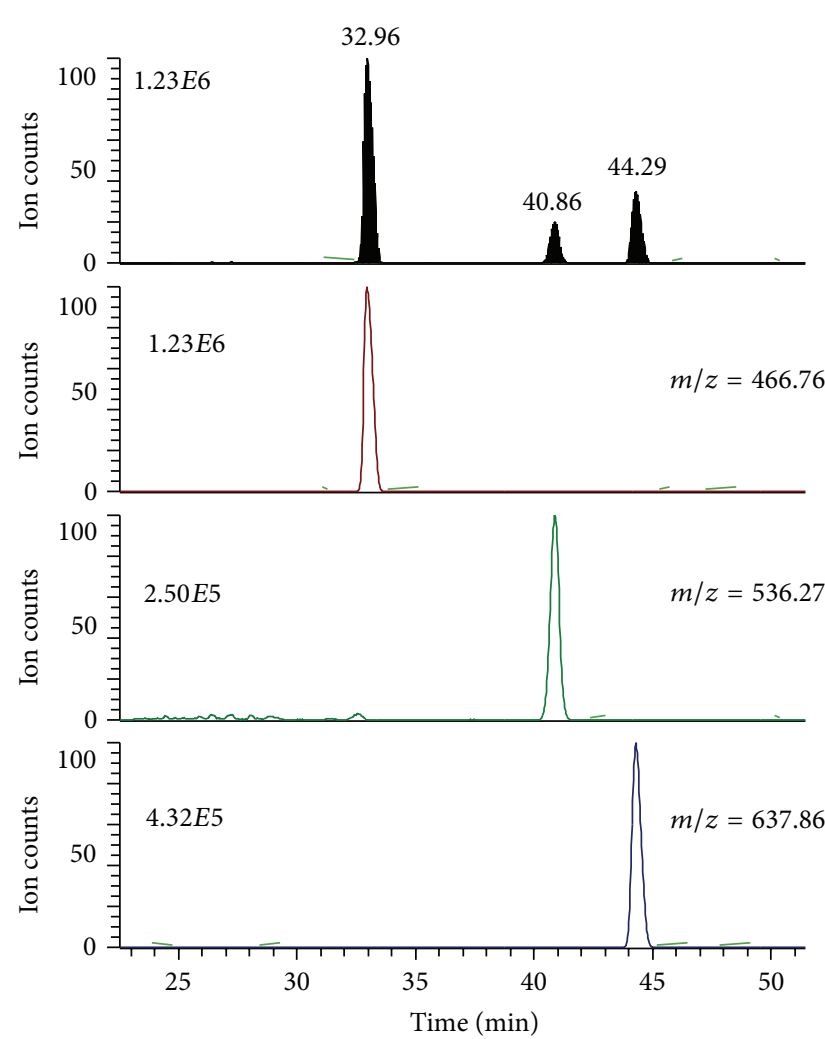

(b) Peptide elution profiles

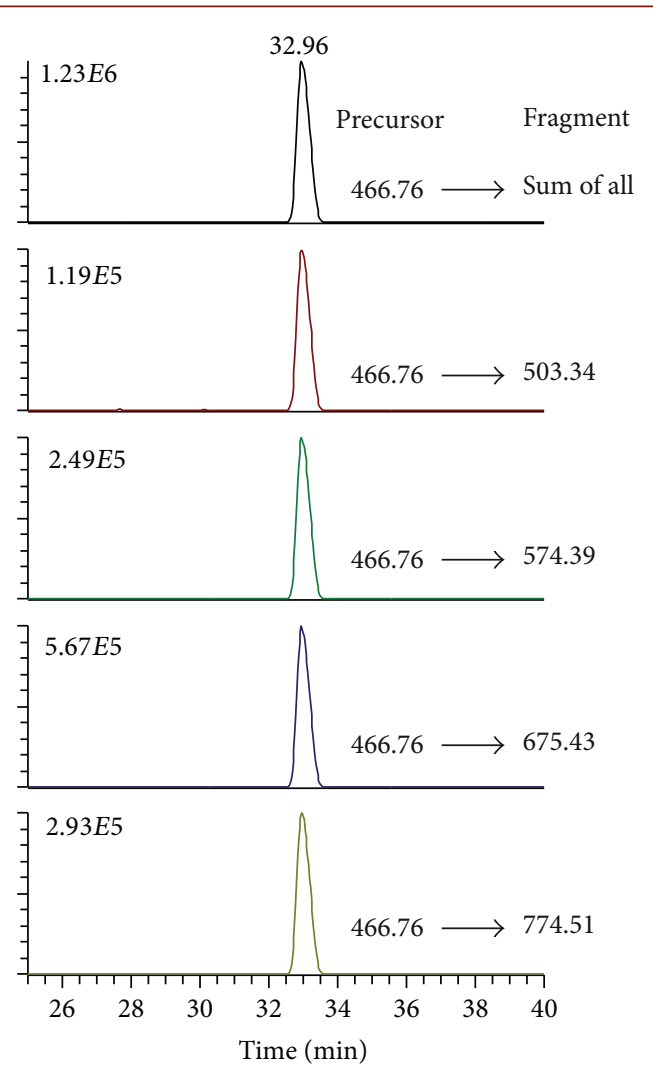

(c) Transitions for $m / z=466.76$

FIGURE 1: SRM of Hb peptides. (a) Amino acid sequences of the alpha and beta chains of $\mathrm{Hb}$. The selected peptides are indicated as bold text (one peptide in the alpha chain, two peptides in the beta chain). (b) Elution chromatography profiles of the three Hb peptides (SAVTALWGK, MFLSFPTTK, and LLVVYPWTQR). (c) Transition profiles of precursor and fragment ions of SAVTALWGK peptide coeluting at 32.96 min.

chloroquine impairs elimination of $\mathrm{Hb}$ by interfering with lysosomal $\mathrm{Hb}$ degradation.

\subsection{Chloroquine Inhibits HO-1 Expression and Creates a} State of Relative Intracellular Iron Deprivation. Heme detoxification relies primarily on inducible HO-1 enzyme, which enables degradation of $\mathrm{Hb}$ to iron, bilirubin, and $\mathrm{CO}[23,24]$. With addition of chloroquine, the strong induction of HO-1 expression, that is, normally observed upon $\mathrm{Hb}: \mathrm{Hp}$ exposure of CD163-HEK-293 cells, is suppressed at the mRNA and protein levels (Figure 4(a)). We confirmed this chloroquine effect also in human peripheral blood monocyte derived macrophages (Figure 4(b)). Also in this cell type, which represents the natural $\mathrm{Hb}$ clearance compartment in human, HO-1 induction by $\mathrm{Hb}: \mathrm{Hp}$ was suppressed by chloroquine.

By limiting $\mathrm{Hb}: \mathrm{Hp}$ triggered HO-1 expression and cellular heme metabolism, chloroquine could profoundly modify macrophage iron homeostasis. We found that exposure to chloroquine in the absence of $\mathrm{Hb}$ stimulated mRNA induction of the transferrin receptor (the principal iron importer) (Figure 4(c)). This implies that under the pharmacologic influence of chloroquine intracellular levels of free iron 


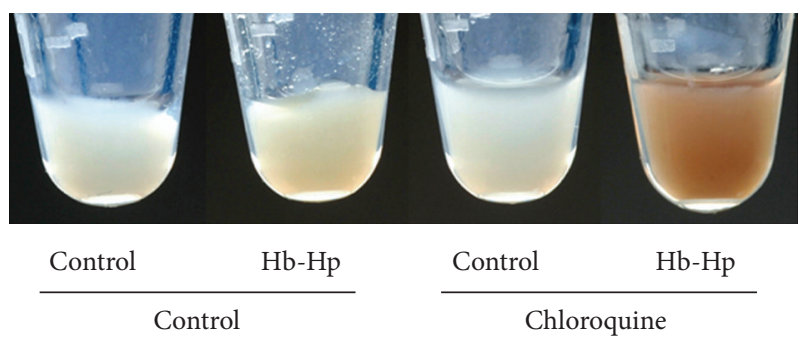

(a)
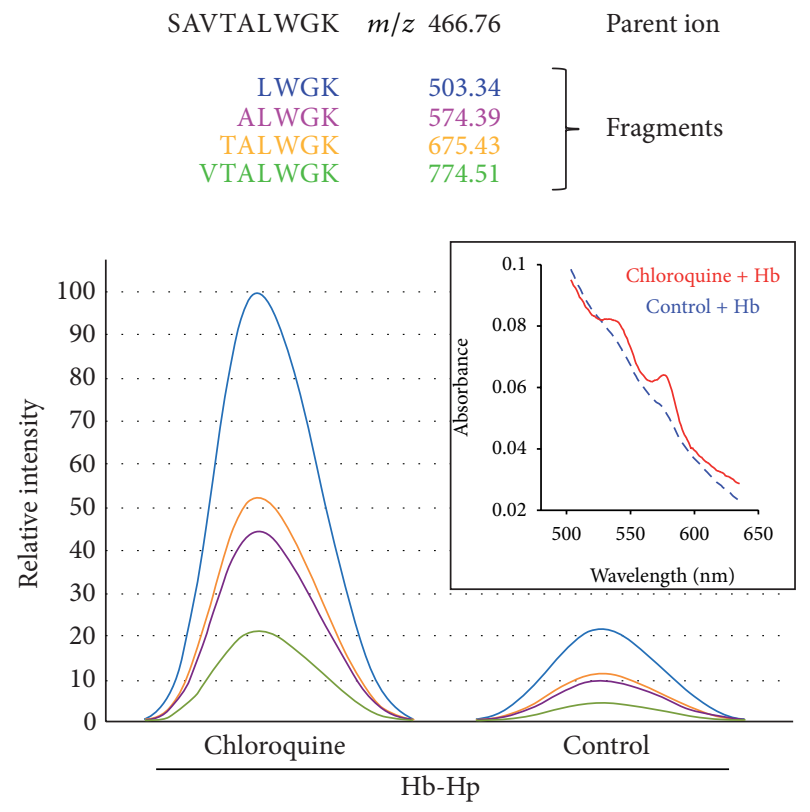

(b)

FIGURE 2: Chloroquine treatment causes intracellular accumulation of heme and globin. (a) CD163-positive HEK cells were exposed to $2 \mathrm{mg} / \mathrm{mL} \mathrm{Hb}: \mathrm{Hp}$ for 12 hours in the presence or absence of chloroquine $(10 \mu \mathrm{M})$. The image shows pellets of extensively washed cells at the end of the treatment period. Chloroquine-treated cells appear intensely red-brown after $\mathrm{Hb}: \mathrm{Hp}$ exposure, indicating high intracellular heme. (b) Integration of fragment-ion signal intensities for the $\mathrm{Hb} \beta$-chain specific peptide SAVTALWGK, as detected by SRM. Sequences and $\mathrm{m} / z$ ratios of the targeted peptide fragments are indicated. The integrated signals confirm that the $\mathrm{Hb}$ peptide accumulates in the chloroquine-treated cells compared to control cells. The insert shows VIS spectra in the range of $500 \mathrm{~nm}-650 \mathrm{~nm}$ of cell lysates, showing a characteristic $\mathrm{Hb}$ absorption component in the chloroquine $+\mathrm{Hb}$ treated cells.

are shifted towards a state of relative iron deprivation. Accordingly, while $\mathrm{Hb}: \mathrm{Hp}$ uptake stimulated mRNA induction of the principal iron exporter ferroportin in untreated macrophages, chloroquine treatment blunts this adaptive response, presumably by limiting iron recovery from $\mathrm{Hb}$ (Figure 4(c)). Collectively, these data support our hypothesis that chloroquine could limit the capacity of macrophages to detoxify heme and to recycle iron.

2.5. Chloroquine Paralyzes Endocytic Hb:Hp Trafficking. As a lysosomotropic agent, chloroquine is likely to alter the dynamics of $\mathrm{Hb}: \mathrm{Hp}$ trafficking though the endosomallysosomal compartments. We performed confocal fluorescence microscopy to examine how chloroquine changes the temporal and spatial relationships of endocytosed $\mathrm{Hb}: \mathrm{Hp}$ with the early endosomal marker transferrin and the lysosome-associated-membrane-protein-1 (LAMP-1). After $15 \mathrm{~min}$ (Figure 5(a)), we found that chloroquine favoured colocalization of endocytosed $\mathrm{Hb}: \mathrm{Hp}$ with the early endosomal marker transferrin, while more Hb:Hp was already transported from early endosomes to LAMP-1-positive lysosomes in untreated cells (Figure 5(b)). Only in the later decay phase, after $40 \mathrm{~min}, \mathrm{Hb}: \mathrm{Hp}$ was found to predominantly colocalize with lysosomal LAMP-1 in chloroquine-treated cells, whereas, in the absence of chloroquine, $\mathrm{Hb}: \mathrm{Hp}$ was largely degraded at this later time point. Both early endosomes and lysosomes showed uniform enlargement under chloroquine.

These data support the contention that chloroquine interferes significantly with endocytic $\mathrm{Hb}: \mathrm{Hp}$ trafficking and degradation, presumably reducing heme access to cytoplasmic HO-1.

\section{Discussion}

Our data provide evidence that chloroquine or its derivatives may interfere with an established pathway for $\mathrm{Hb}$ clearance, thereby inhibiting heme detoxification and, potentially, heme-iron recycling. Specifically, we found that chloroquine blocks $\mathrm{Hb}: \mathrm{Hp}$ degradation by paralyzing lysosomal function and limiting heme access to $\mathrm{HO}-1$, the primary enzyme of Hb-heme catabolism.

For this study, we developed a method to track intracellular globin concentration after endocytosis of $\mathrm{Hb}: \mathrm{Hp}$ complexes. Although assays by spectrophotometry might enable $\mathrm{Hb}$ quantification in cells, based on the characteristic absorption spectra of its heme moiety, quantification of the protein itself remains challenging. Flow-cytometry assays, as alternative methods, require fluorescent tracers, which may alter the natural elimination rate of a target protein or metabolically skew a protein of interest. Furthermore, the elimination of the fluorescent tracer may disconnect from heme/ $\mathrm{Hb}$ elimination in the acidic and proteolytic environment of the lysosomes.

Selected reaction monitoring (SRM) represents a powerful and sensitive alternative method that allows direct and sequence-specific protein measurement at very lowconcentration. Therefore, we developed an SRM based method to determine relative intracellular $\mathrm{Hb}$ concentrations and track the decay rate of $\mathrm{Hb}$-specific peptides after endocytosis. Our SRM method may be of use in other experimental settings to evaluate hemolytic processes, tissue distribution of free $\mathrm{Hb}$, and $\mathrm{Hb}$ metabolism in various disease states. Furthermore, similar assays may be developed to monitor dynamic trafficking and clearance processes of other proteins. Similar methods have been used previously to quantitatively study dynamic interaction of endocytic receptors with protein ligands and to investigate protein catabolic processes $[25,26]$. 


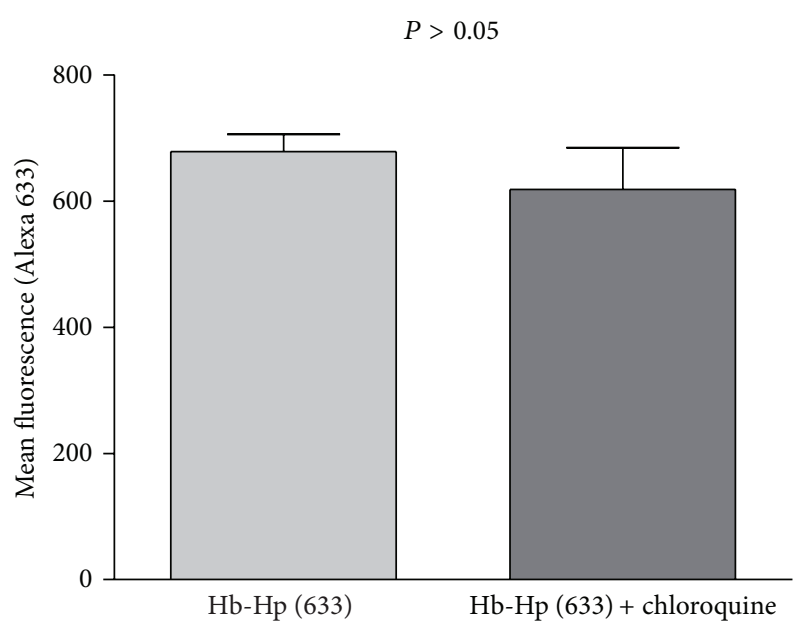

(a)
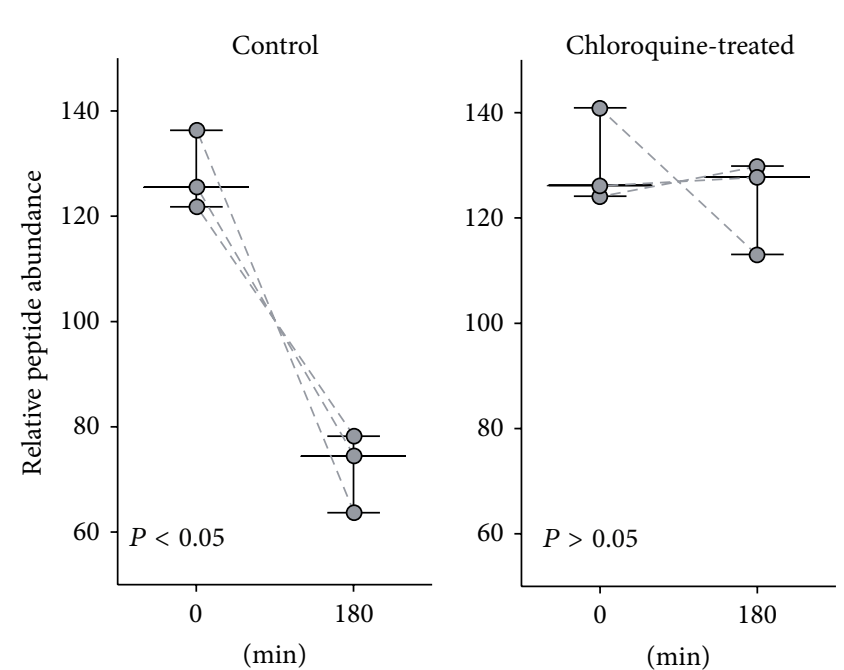

(b)

Figure 3: Chloroquine impairs Hb degradation but not primary cellular Hb uptake. (a) Fluorescent Hb:Hp (Alexa 633) uptake capacity of chloroquine pretreated $(30 \mathrm{~min}$ ) and control CD163-positive HEK cells (values given as mean \pm SEM of channel fluorescence from three independent experiments). No statistical difference was observed $(P>0.05)$. (b) CD163-positive HEK cells, with and without chloroquine pretreatment (as shown in Figure 2), were incubated for 12 hours with $\mathrm{Hb}: \mathrm{Hp} 2 \mathrm{mg} / \mathrm{mL}$. After removing Hb from culture medium by extensive washing, the cell samples were either immediately lysed or further incubated for $180 \mathrm{~min}$ before intracellular Hb-specific peptides were relatively quantified by SRM. The following three $\mathrm{Hb}$ peptides were monitored and are individually represented in the graph: SAVTALGK, MFLSFPTTK, and LLVVYPWTQR (see Figure 1). The Hb decay is significantly less in the chloroquine-treated cells (control 0 versus 180 min $P<0.05$, chloroquine-treated 0 versus $180 \mathrm{~min} P>0.05$ ). Data points represent mean peptide abundance values that were determined in three independent experiments.

Under our experimental conditions, which involved drug concentrations within the range of peak plasma concentrations measured in chloroquine-treated patients $[27,28]$, the agent does not impair initial endocytosis of $\mathrm{Hb}: \mathrm{Hp}$ complexes by the CD163 scavenger receptor. However, chloroquine treatment drastically slows the decay rate of $\mathrm{Hb}$. The resulting massive $\mathrm{Hb}$ accumulation is attributable to the known lysosomotropic action of this agent. Apparently, degradation of $\mathrm{Hb}$ requires an intact lysosomal system for cytoplasmic delivery of Hb-derived heme and further catabolism by HO-1. Morphologically, the result of deregulated $\mathrm{Hb}$ trafficking becomes apparent as a global congestive enlargement of lysosomes that we observed by confocal microscopy. In chloroquine-treated cells the $\mathrm{Hb}: \mathrm{Hp}$ complexes are stacked within the early endosomal compartment, reaching the lysosome compartment only 40-minutes after completed endocytosis. Normally, trafficking of $\mathrm{Hb}: \mathrm{Hp}$ complexes through the endosomal-lysosomal compartment is largely completed at this time point.

We have previously shown that $\mathrm{Hb}$-heme internalization by CD163 induces high levels of HO-1 mRNA and protein expression $[7,29]$. Upon treatment with chloroquine, $\mathrm{Hb}$ is still internalized into the endocytic compartment by CD163 receptor, but the HO-1 expression is abolished, possibly due to limited delivery of $\mathrm{Hb}$-derived heme into the cytoplasm. $\mathrm{HO}-1$ is pivotal in preventing $\mathrm{Hb}$ toxicity by catabolizing heme to the anti-inflammatory and antioxidant byproducts: bilirubin, carbon monoxide, and ferritin [23, 24]. However, if this protective mechanism is suppressed, susceptibility to the oxidative and proinflammatory toxicities of extracellular $\mathrm{Hb}$ may increase, particularly during acute hemolytic episodes.

It could be hypothesized that inhibition of $\mathrm{Hb}$ detoxification by chloroquine treatment could be particularly deleterious in patients infected with chloroquine resistant plasmodium parasites. The 1.63 -fold increased risk of cerebral malaria and 4-fold increased risk of mortality in chloroquinetreated children that was observed in a study of hometreatment strategies for febrile children in Nigeria could endorse this hypothesis [30].

We also found that chloroquine adversely modifies $\mathrm{Hb}: \mathrm{Hp}$ triggered adaptation of iron homeostasis in human macrophages preventing release of heme iron into the recycle pathway. Under normal conditions, the heme-iron load, which is imparted by endocytosis of $\mathrm{Hb}: \mathrm{Hp}$ complexes, causes a rapid downregulation of the transferrin receptor and a concurrent induction of the iron exporter ferroportin [8]. This adaptive response assures that iron homeostasis is shifted towards enhanced iron supply to the bone marrow, which is a critical process in hemolytic anemia [31]. Chloroquine treatment appears to suppress this adaptive gene regulation and may therefore impair heme-iron recycling.

In conclusion, our studies indicate that chloroquine interferes with the detoxification pathway of extracellular $\mathrm{Hb}$. In some conditions chloroquine treatment may therefore aggravate the deleterious effects of hemolysis, limiting erythropoietic heme-iron supply and promoting inflammation and tissue damage in patients with malaria or autoimmune hemolytic anemia. 

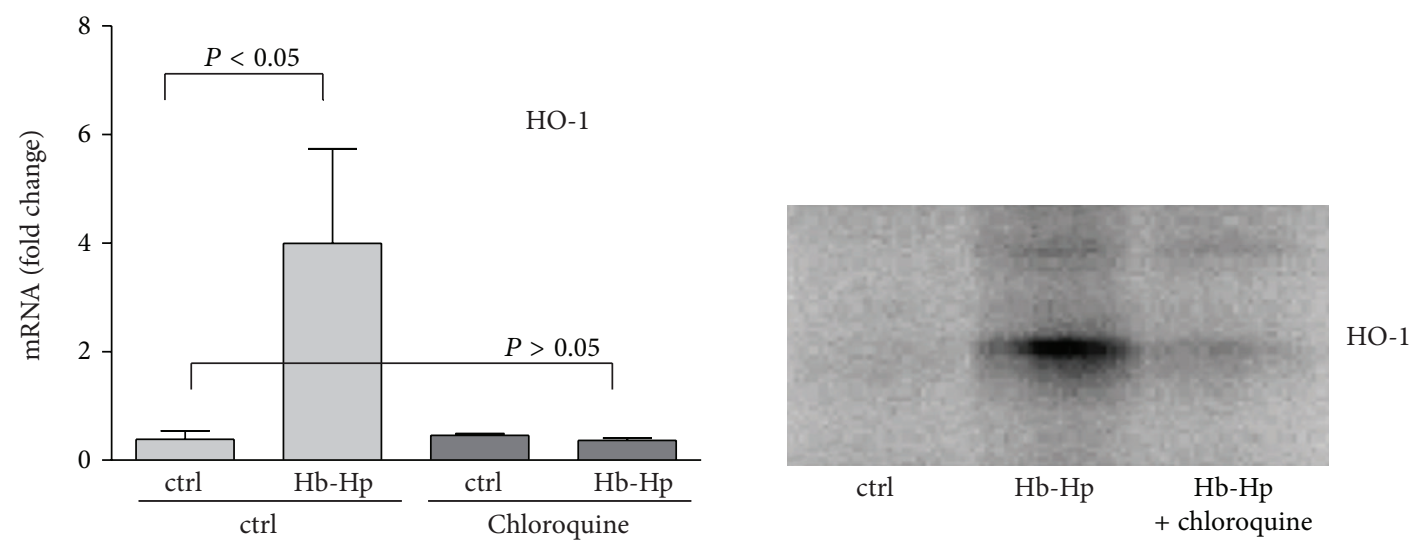

(a)
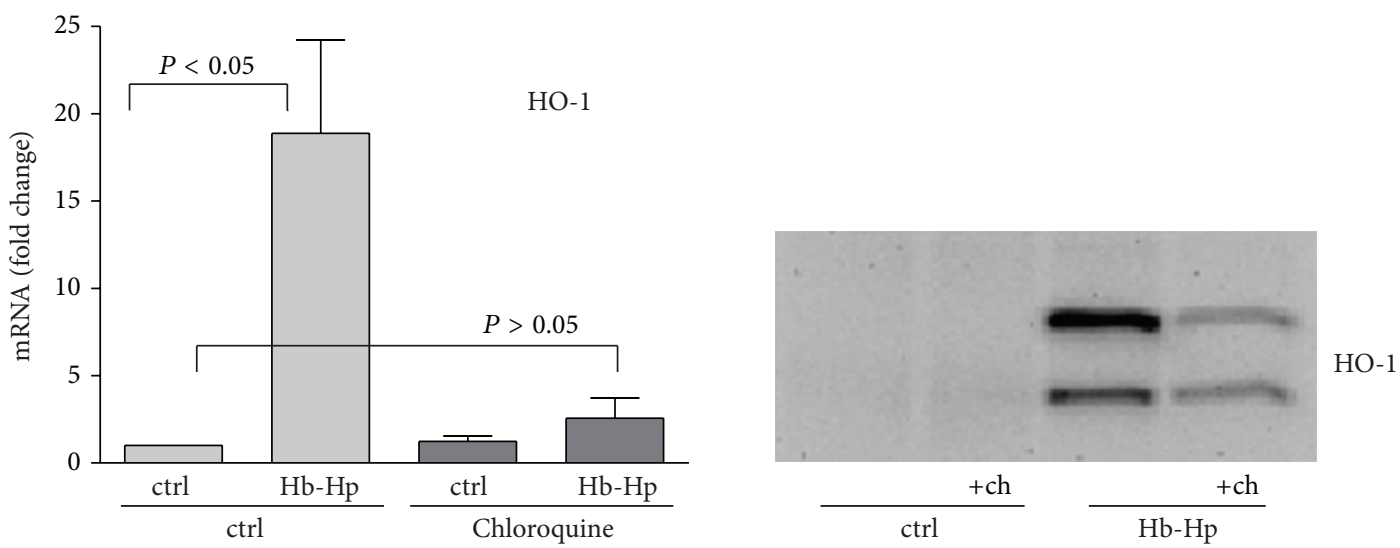

(b)
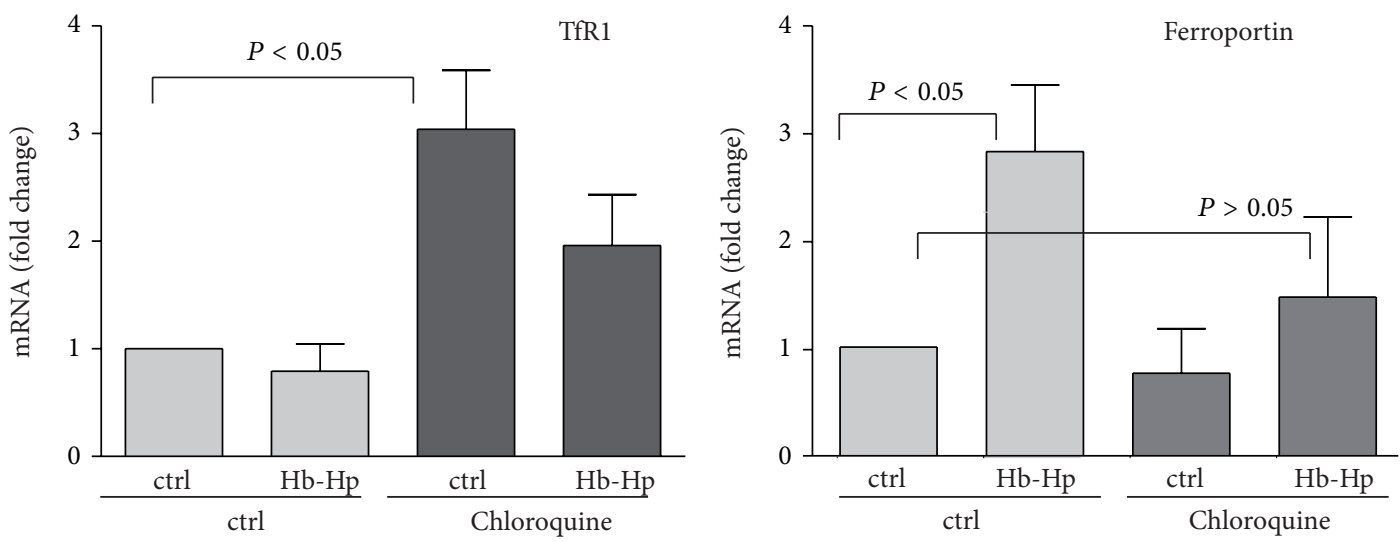

(c)

FIGURE 4: Chloroquine treatment attenuates the cellular HO-1 and iron metabolism response to Hb:Hp exposure. (a) Relative mRNA (left) and protein (right, Western blot) expression levels of HO-1 in chloroquine-treated and untreated CD163-positive HEK cells after stimulation with $\mathrm{Hb}: \mathrm{Hp}(2 \mathrm{mg} / \mathrm{mL})$ for 8 hours (values represent mean \pm SEM of at least three independent experiments). (b) Relative mRNA (left) and protein (right, Western blot) expression levels of HO-1 in human monocyte derived macrophages after Hb:Hp ( $2 \mathrm{mg} / \mathrm{mL}$ ) exposure for 8 hours in the presence or absence of chloroquine. (c) Relative changes of transferrin receptor (TfR1) and ferroportin mRNA expression in human monocyte derived macrophages after $\mathrm{Hb}: \mathrm{Hp}(2 \mathrm{mg} / \mathrm{mL})$ exposure for 8 hours in the presence or absence of chloroquine. All mRNA changes are given relative to control cells (data indicate mean \pm SEM of at least three independent experiments). 

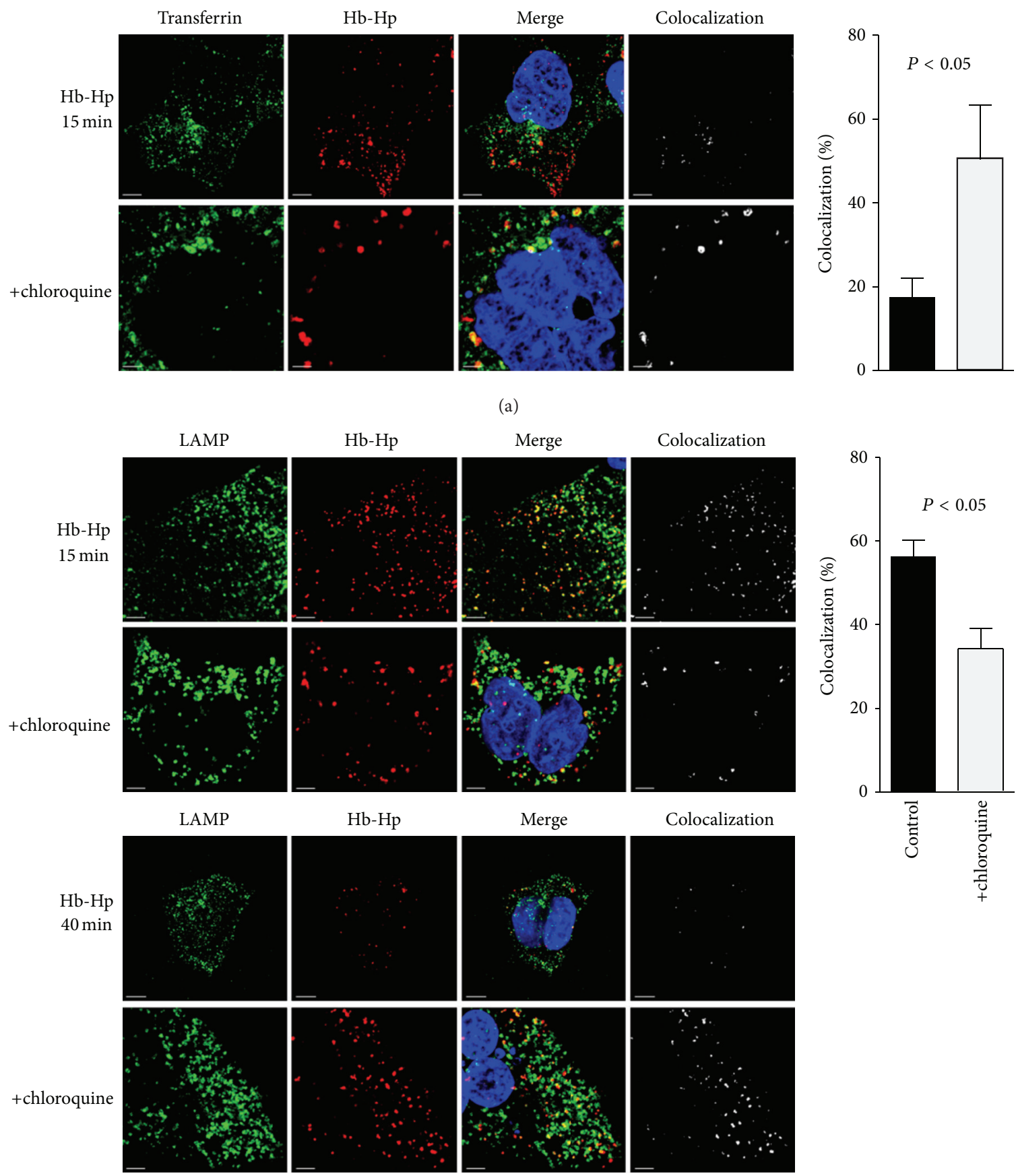
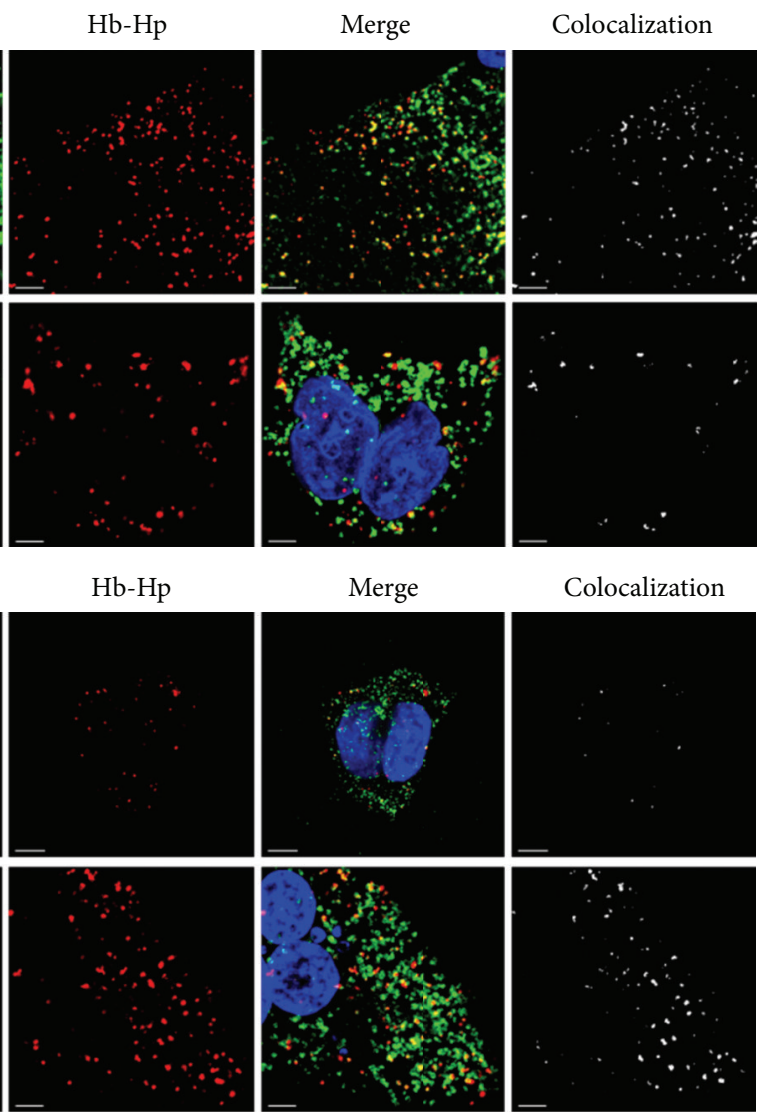

(b)

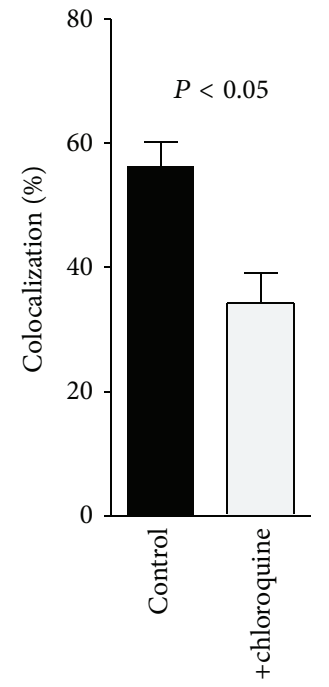

FIGURE 5: Chloroquine impairs Hb:Hp trafficking through the endosomal-lysosomal compartment. (a) CD163-positive HEK cells incubated $15 \mathrm{~min}$ after endocytosis with Alexa 594-labeled $\mathrm{Hb}: \mathrm{Hp}$ complexes and Alexa 488-labeled transferrin, with and without chloroquine pretreatment. The proportion of endocytosed $\mathrm{Hb}: \mathrm{Hp}$ complexes colocalizing with the early endosomal compartment (transferrin-positive) increases substantially after chloroquine exposure. (b) CD163-positive HEK cells incubated for 15 min (upper two rows) or 40 min (lower two rows) after endocytosis with Alexa 594-labeled Hb:Hp complexes. The lysosomal compartment is stained with anti-LAMP-1 antibody and Alexa 488-labeled secondary antibody. Early colocalization of Hb:Hp complexes in the lysosomal (LAMP-1) compartment after 15 min is considerably reduced by pretreatment with chloroquine. In contrast, after $40 \mathrm{~min}$, chloroquine pretreatment leads to marked accumulation of $\mathrm{Hb}: \mathrm{Hp}$ complexes in the lysosomes. Optical magnification of all images is 630x. DAPI-stained nuclei are blue, and scale bars are spaced at $5 \mu \mathrm{m}$. The percentage of colocalization is shown in the graphs on the right with black bars indicating control cells and gray bars indicating chloroquine-treated cells; $n=4-5$ images per condition that were recorded on independent samples. 


\section{Material and Methods}

4.1. HEK Cells Transfection and Culture. Human-embryonickidney- (HEK-) 293 cells (Invitrogen, Basel, Switzerland) were cultured in DMEM (Invitrogen) containing 10\% FCS (Invitrogen). CD163-expressing lentiviral-transduced HEK293 cells were generated as described elsewhere [5] and maintained with $5 \mu \mathrm{g} / \mathrm{mL}$ blasticidin (Invitrogen), which was removed from cultures at least one cell passage prior to experiments.

4.2. Macrophage Isolation. Human-blood-derived monocytes were prepared from buffy coats of healthy donors, as purchased from the Swiss Red Cross Blood Bank (Swiss Red Cross) and already described [32]. These cells were cultured in Iscove modified Dulbecco medium (Invitrogen), supplemented by $10 \%$ heat-inactivated, pooled human serum having negligible residual free $\mathrm{Hb}$ by design. Written informed consent was obtained from all donors, in accordance with the Declaration of Helsinki, and all the work was approved by the ethics review board of the Canton of Zurich.

\subsection{Proteomic Sample Preparation and TSQ Mass-Spectrom-} etry. Total cellular protein was extracted using CelLytic-M reagent (Sigma-Aldrich) supplemented by Complete Mini Protease Inhibitor (Roche Diagnostics). After three freezethaw cycles, cellular debris was removed by a 30 -minute centrifugation $(16000 \times \mathrm{g})$.

The protein concentration of each sample was determined using Bradford assay (Bio-Rad, Hercules, CA, USA). Samples were precipitated by adding TCA (10\% final concentration) and incubated on ice for $20 \mathrm{~min}$. Following centrifugation $(14000 \times \mathrm{g})$, the supernatant was removed, and the pellets were triple-washed in ice-cold acetone. Afterward, they were dried $5 \mathrm{~min}$ at $95^{\circ} \mathrm{C}$ and reconstituted in $0.1 \%$ RapiGest (Waters). Disulfide bonds were reduced by DTT additive and finally blocked by treatment with iodoacetamide. The pellets were next subjected to overnight digestion by trypsin $(1: 10$ ratio, trypsin to protein) at $37^{\circ} \mathrm{C}$. Lyophilized peptide mixtures were ultimately dissolved in $5 \% \mathrm{ACN}$ and $0.1 \%$ formic acid for loading onto a $5 \mu \mathrm{m} \mathrm{C18} \mathrm{column} \mathrm{(PicoFrit} \mathrm{Column}$ Hyp. Gold, AQ $5 \mu \mathrm{m}, 75 \mu \mathrm{m} \times 100 \mathrm{~mm}$, New Objective Inc.).

A TSQ Vantage Triple Quadrupole mass spectrometer (Thermo Fisher Scientific, Waltham, MA, USA), equipped with a nanoelectrospray ionization source, was used for SRM measurements. Chromatographic peptide separations were performed on an Eksigent 1D Nano-LC system (Eksigent Technologies), applying a $55 \mathrm{~min}$ gradient from 5 to $50 \% \mathrm{v} / \mathrm{v}$ acetonitrile in water, both amended with $0.1 \% \mathrm{v} / \mathrm{v}$ formic acid. The LC operational flow rate was $500 \mathrm{~nL} \mathrm{~min}^{-1}$. Massspectrometry was done in SRM mode; Q1 and Q3 were set at resolutions 0.2 and $0.7 \mathrm{Da}$, respectively. A spray voltage of $+1400 \mathrm{~V}$ was used with a heated ion transfer capillary setting of $120^{\circ} \mathrm{C}$ for desolvation. A $20 \mathrm{~ms}$ dwell time was set, with $0.002 \mathrm{~m} / z$ scan width.

4.4. Analysis by Selected Reaction Monitoring. SRM methods were developed and optimized as described elsewhere
[33-35]. Tryptic peptides lacking methionine or cysteine were measured, and transitions (for three peptides per protein) were selected considering first maximum signal intensities observed during LC-MS/MS, with further refinement with respect to signal-to-noise measurements during the SRM trials. SRM peak areas were calculated by using Pinpoint software (Thermo Fisher Scientific, Waltham, MA, USA). All SRM measurements were performed on three biologic replicates.

4.5. Quantitative Real-Time Reverse Transcription-Polymerase Chain Reaction (RT-PCR). Real-time RT-PCR was performed on a Fast Real-Time PCR System Instrument (Applied Biosystems) using TaqMan reverse transcription and SYBR Green master mix PCR reagents (Applied Biosystems) as described. Gene-specific quantitative data were corrected for HPRT mRNA abundance in the respective samples and are expressed as fold expression relative to the control.

4.6. Western Blot Analysis. Western blots were performed using standard techniques and a single primary HO-1 antibody (SPA-896; Stressgen). Sample loading was adjusted for equal protein per lane after measurement of the protein concentration by Bradford assay (Bio-Rad, Hercules, CA, USA). The horseradish peroxidase-conjugated secondary antibodies (Amersham Biosciences) used for detection were diluted 1:10000. Blots were developed with ECL Plus Western blotting detection reagent (Amersham Biosciences) and analyzed on a ChemiDoc XRS system with Quantity One 1-D Analysis software, version 4.5.0 (Bio-Rad).

4.7. Analysis of Fluorescent Hb:Hp Uptake. CD163-transduced HEK-293 were incubated for $30 \mathrm{~min}$ at $37^{\circ} \mathrm{C}$ with Alexa 633-labeled Hb:Hp (3 $\mu \mathrm{g} / \mathrm{mL})$ [32]. The cells were washed with EDTA containing buffer and resuspended in phosphatebuffered saline (PBS) for analysis by a FACSCalibur (Becton Dickinson). Data were analyzed with CellQuest (Becton Dickinson).

4.8. Confocal Fluorescence Microscopy. For fluorescence microscopy, HEK cells were cultured on baked $(4 \mathrm{~h}$ at $220^{\circ} \mathrm{C}$ ), endotoxin-free, sterile, round, $12 \mathrm{~mm}$ glass coverslips (Hecht-Assistent, Germany), placed in 24-cluster wells, and pretreated $2 \mathrm{~h}$ before examination with $6.25 \mathrm{mcg} / \mathrm{cm}^{2}$ poly-D-lysine hydrobromide (BD Biosciences, San Jose, CA, USA). Pretreatment with chloroquine $(10 \mu \mathrm{M})$ lasted $12 \mathrm{~h}$. Fluorescent-labeled Hb:Hp complexes (with or without fluorescent transferrin) required a $15 \mathrm{~min}$ incubation in cell culture medium containing $10 \%$ FCS. To determine subcellular localization of $\mathrm{Hb}: \mathrm{Hp} 15$ or $40 \mathrm{~min}$ after endocytosis, the medium was changed, and a second incubation (with or without transferrin) followed in the absence of fluorescent $\mathrm{Hb}: \mathrm{Hp}$ complexes. Labeling of Hp (Sigma Chemical Co.) was done using Alexa 594 protein-labeling kit (Molecular Probes, Eugene, OR, USA). Hb:Hp complexes were generated by combining $\mathrm{Hb}$ and fluorescent $\mathrm{Hp}$ at a 1:1 molar ratio, 10 min before examination. Hb:Hp complexes were employed at $10 \mu \mathrm{g} / \mathrm{mL}$ concentration. Transferrin was labeled using the 
Alexa 488 protein-labeling kit and employed at $20 \mu \mathrm{g} / \mathrm{mL}$ concentration. Finally, the cells were triple-washed with PBS, pH 7.4 (Sigma Chemical Co., St. Louis, MO, USA), fixed 15 min in PBS with 2.5\% paraformaldehyde, and permeabilized for $5 \mathrm{~min}$ at room temperature in $0.1 \%$ Triton X-100 (Sigma Chemical Co.) and PBS. After washing, nonspecific binding sites were blocked for $1 \mathrm{~h}$ in $10 \%$ goat serum and PBS, supplemented with $1 \%$ bovine serum albumin ((BSA) Sigma Chemical Co.), again at room temperature.

Staining of LAMP-1 was accomplished by incubation $1 \mathrm{~h}$ at room temperature with mouse anti-LAMP-1 antibody (RDI Research Diagnostics, Concord, MA, USA), diluted $1: 800$ in PBS supplemented by $1 \%$ goat serum and $0.1 \%$ BSA. Alexa Fluor 488 goat anti-mouse IgG (Molecular Probes) served as a secondary antibody, using $10 \mu \mathrm{g} / \mathrm{mL} 4,6-$ diamidino-2-phenylindole ((DAPI) Sigma Chemical Co.) as a nuclear counterstain. After three washes in PBS, coverslips were applied using ProLong Gold antifade reagentmounting medium (Molecular Probes). Optical sections at $0.125 \mu \mathrm{m}$ were viewed under a Leica SP5 confocal laserscanning microscope (Leica, Heidelberg, Germany), using default magnification of 630x. Images were imported into Imaris software, version 6.1.2 (Bitplane Scientific Software, Zurich, Switzerland).

The extent of colocalization was quantified on the basis of intensity per colocalization module in Imaris. To differentiate fluorescent $\mathrm{Hb}: \mathrm{Hp}$ (red channel) colocalization with transferrin or LAMP-1 (both green channel), the red channel contribution to colocalized areas was analyzed using a fixed threshold of 127.5 in both channel histograms.

4.9. Statistical Analysis. Data were analyzed with GraphPad Prism version 4.0. We used an unpaired 2-tailed Student's $t$ test for comparisons of groups, with ANOVA where applicable. $P$ values $<0.05$ were considered statistically significant.

\section{Abbreviations}

Hb: Hemoglobin

Hp: Haptoglobin

HO-1: Heme-oxygenase-1

GAPDH: Glyceraldehyde-3-phosphate dehydrogenase

LAMP-1: Lysosomal-associated-membrane-protein-1

SRM: $\quad$ Single reaction monitoring

ACN: Acetonitrile.

\section{Conflicts of Interests}

The authors declare no conflict of interests.

\section{Acknowledgments}

This work was supported by the University of Zurich "Forschungskredit" and by the Swiss National Science Foundation (Grants 310030/120658 and 31003A/138500).

\section{References}

[1] D. J. Schaer, P. W. Buehler, A. I. Alayash, J. D. Belcher, and G. M. Vercellotti, "Hemolysis and free hemoglobin revisited: exploring hemoglobin and hemin scavengers as a novel class of therapeutic proteins," Blood, vol. 121, no. 8, pp. 1276-1284, 2013.

[2] P. W. Buehler, F. D’Agnillo, and D. J. Schaer, "Hemoglobin-based oxygen carriers: from mechanisms of toxicity and clearance to rational drug design," Trends in Molecular Medicine, vol. 16, no. 10, pp. 447-457, 2010.

[3] D. J. Schaer and A. I. Alayash, "Clearance and control mechanisms of hemoglobin from cradle to grave," Antioxidants and Redox Signaling, vol. 12, no. 2, pp. 181-184, 2010.

[4] M. Kristiansen, J. H. Graversen, C. Jacobsen et al., "Identification of the haemoglobin scavenger receptor," Nature, vol. 409, no. 6817 , pp. 198-201, 2001.

[5] D. J. Schaer, C. A. Schaer, P. W. Buehler et al., "CD163 is the macrophage scavenger receptor for native and chemically modified hemoglobins in the absence of haptoglobin," Blood, vol. 107, no. 1, pp. 373-380, 2006.

[6] C. A. Schaer, F. Vallelian, A. Imhof, G. Schoedon, and D. J. Schaer, "CD163-expressing monocytes constitute an endotoxinsensitive $\mathrm{Hb}$ clearance compartment within the vascular system," Journal of Leukocyte Biology, vol. 82, no. 1, pp. 106-110, 2007.

[7] C. A. Schaer, G. Schoedon, A. Imhof, M. O. Kurrer, and D. J. Schaer, "Constitutive endocytosis of CD163 mediates hemoglobin-heme uptake and determines the noninflammatory and protective transcriptional response of macrophages to hemoglobin," Circulation Research, vol. 99, no. 9, pp. 943-950, 2006.

[8] F. Vallelian, C. A. Schaer, T. Kaempfer et al., "Glucocorticoid treatment skews human monocyte differentiation into a hemoglobin-clearance phenotype with enhanced heme-iron recycling and antioxidant capacity," Blood, vol. 116, no. 24, pp. 5347-5356, 2010.

[9] M. B. Maniecki, H. Hasle, L. Friis-Hansen et al., "Impaired CD163-mediated hemoglobin-scavenging and severe toxic symptoms in patients treated with gemtuzumab ozogamicin," Blood, vol. 112, no. 4, pp. 1510-1514, 2008.

[10] A. Yachie, Y. Niida, T. Wada et al., "Oxidative stress causes enhanced endothelial cell injury in human heme oxygenase-1 deficiency," Journal of Clinical Investigation, vol. 103, no. 1, pp. 129-135, 1999.

[11] R. Wattiaux, N. Laurent, S. Wattiaux-De Coninck, and M. Jadot, "Endosomes, lysosomes: their implication in gene transfer," Advanced Drug Delivery Reviews, vol. 41, no. 2, pp. 201-208, 2000.

[12] R. E. Chapman and S. Munro, "Retrieval of TGN proteins from the cell surface requires endosomal acidification," $E M B O$ Journal, vol. 13, no. 10, pp. 2305-2312, 1994.

[13] I. Mallman, R. Fuchs, and A. Helenius, "Acidification of the endocytic and exocytic pathways," Annual Review of Biochemistry, vol. 55, pp. 663-700, 1986.

[14] E. Hempelmann, "Hemozoin biocrystallization in Plasmodium falciparum and the antimalarial activity of crystallization inhibitors," Parasitology Research, vol. 100, no. 4, pp. 671-676, 2007.

[15] A. Pamplona, A. Ferreira, J. Balla et al., "Heme oxygenase-1 and carbon monoxide suppress the pathogenesis of experimental cerebral malaria," Nature Medicine, vol. 13, no. 6, pp. 703-710, 2007.

[16] S. C. Murphy and J. G. Breman, "GAPS in the childhood malaria burden in Africa: cerebral malaria, neurological sequelae, anemia, respiratory distress, hypoglycemia, and complications of 
pregnancy," American Journal of Tropical Medicine and Hygiene, vol. 64, no. 1-2, pp. 57-67, 2001.

[17] J. R. Zucker, E. M. Lackritz, T. K. Ruebush et al., "Childhood mortality during and after hospitalization in western Kenya: effect of malaria treatment regimens," American Journal of Tropical Medicine and Hygiene, vol. 55, no. 6, pp. 655-660, 1996.

[18] E. M. Lackritz, C. C. Campbell, T. K. Ruebush et al., "Effect of blood transfusion on survival among children in a Kenyan hospital," The Lancet, vol. 340, no. 8818, pp. 524-528, 1992.

[19] N. K. Shah, G. P. S. Dhillon, A. P. Dash, U. Arora, S. R. Meshnick, and N. Valecha, "Antimalarial drug resistance of Plasmodium falciparum in India: changes over time and space," The Lancet Infectious Diseases, vol. 11, no. 1, pp. 57-64, 2011.

[20] R. T. Eastman and D. A. Fidock, "Artemisinin-based combination therapies: a vital tool in efforts to eliminate malaria," Nature Reviews Microbiology, vol. 7, no. 12, pp. 864-874, 2009.

[21] G. Ruiz-Irastorza, M. Ramos-Casals, P. Brito-Zeron, and M. A. Khamashta, "Clinical efficacy and side effects of antimalarials in systemic lupus erythematosus: a systematic review," Annals of the Rheumatic Diseases, vol. 69, no. 1, pp. 20-28, 2010.

[22] S. J. Lee, E. Silverman, and J. M. Bargman, "The role of antimalarial agents in the treatment of SLE and lupus nephritis," Nature Reviews Nephrology, vol. 7, no. 12, pp. 718-729, 2011.

[23] N. G. Abraham and A. Kappas, "Pharmacological and clinical aspects of heme oxygenase," Pharmacological Reviews, vol. 60, no. 1, pp. 79-127, 2008.

[24] J. Balla, G. M. Vercellotti, V. Jeney et al., "Heme, heme oxygenase, and ferritin: how the vascular endothelium survives (and dies) in an iron-rich environment," Antioxidants and Redox Signaling, vol. 9, no. 12, pp. 2119-2137, 2007.

[25] J. R. Krieger, P. Taylor, A. S. Gajadhar, A. Guha, M. F. Moran, and C. J. McGlade, "Identification and selected reaction monitoring (SRM) quantification of endocytosis factors associated with Numb," Molecular and Cellular Proteomics, vol. 12, no. 2, pp. 499-514, 2013.

[26] N. J. Agard, S. Mahrus, J. C. Trinidad, A. Lynn, A. L. Burlingame, and J. A. Wells, "Global kinetic analysis of proteolysis via quantitative targeted proteomics," Proceedings of the National Academy of Sciences of the United States of America, vol. 109, no. 6, pp. 1913-1918, 2012.

[27] I. F. Khalil, M. Alifrangis, C. Recke et al., "Development of ELISA-based methods to measure the anti-malarial drug chloroquine in plasma and in pharmaceutical formulations," Malaria Journal, vol. 10, article 249, 2011.

[28] H. S. Lim, J. S. Im, J. Y. Cho et al., "Pharmacokinetics of hydroxychloroquine and its clinical implications in chemoprophylaxis against malaria caused by plasmodium vivax," Antimicrobial Agents and Chemotherapy, vol. 53, no. 4, pp. 1468-1475, 2009.

[29] P. W. Buehler, F. Vallelian, M. G. Mikolajczyk et al., "Structural stabilization in tetrameric or polymeric hemoglobin determines its interaction with endogenous antioxidant scavenger pathways," Antioxidants and Redox Signaling, vol. 10, no. 8, pp. 14491462, 2008.

[30] A. E. Orimadegun, O. K. Amodu, P. E. Olumese, and O. O. Omotade, "Early home treatment of childhood fevers with ineffective antimalarials is deleterious in the outcome of severe malaria," Malaria Journal, vol. 7, article 143, 2008.

[31] T. Ganz and E. Nemeth, "Iron metabolism: interactions with normal and disordered erythropoiesis," Cold Spring Harbor Perspectives in Medicine, vol. 2, no. 5, Article ID 011668, 2012.
[32] D. J. Schaer, F. S. Boretti, G. Schoedon, and A. Schaffner, "Induction of the CD163-dependent haemoglobin uptake by macrophages as a novel anti-inflammatory action of glucocorticoids," British Journal of Haematology, vol. 119, no. 1, pp. 239243, 2002.

[33] P. Picotti and R. Aebersold, "Selected reaction monitoringbased proteomics: workflows, potential, pitfalls and future directions," Nature Methods, vol. 9, no. 6, pp. 555-566, 2012.

[34] A. Maiolica, M. A. Junger, I. Ezkurdia, and R. Aebersold, “Targeted proteome investigation via selected reaction monitoring mass spectrometry," Journal of Proteomics, vol. 75, no. 12, pp. 3495-3513, 2012.

[35] P. Picotti, O. Rinner, R. Stallmach et al., "High-throughput generation of selected reaction-monitoring assays for proteins and proteomes," Nature Methods, vol. 7, no. 1, pp. 43-46, 2010. 


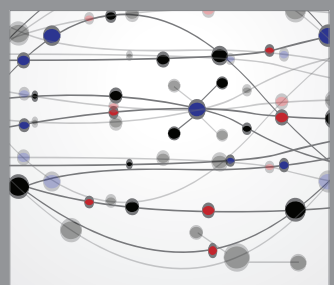

The Scientific World Journal
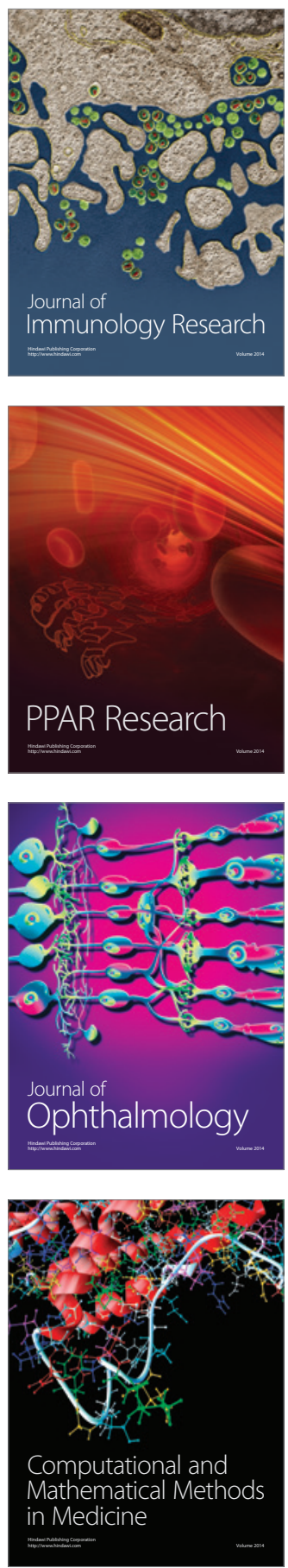

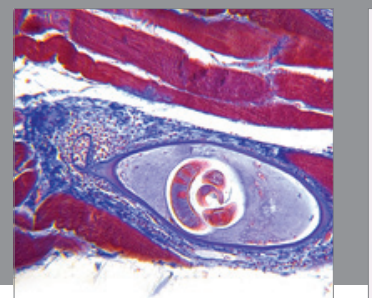

Gastroenterology

Research and Practice
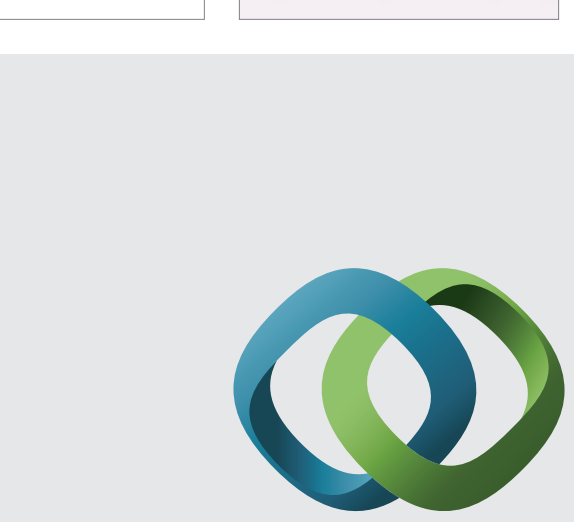

\section{Hindawi}

Submit your manuscripts at

http://www.hindawi.com
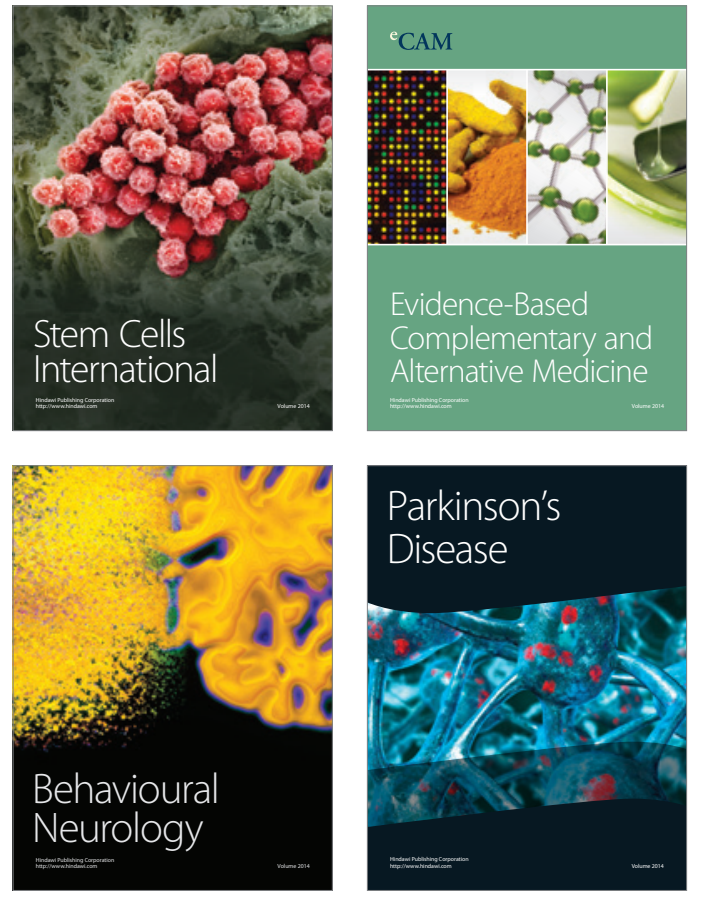
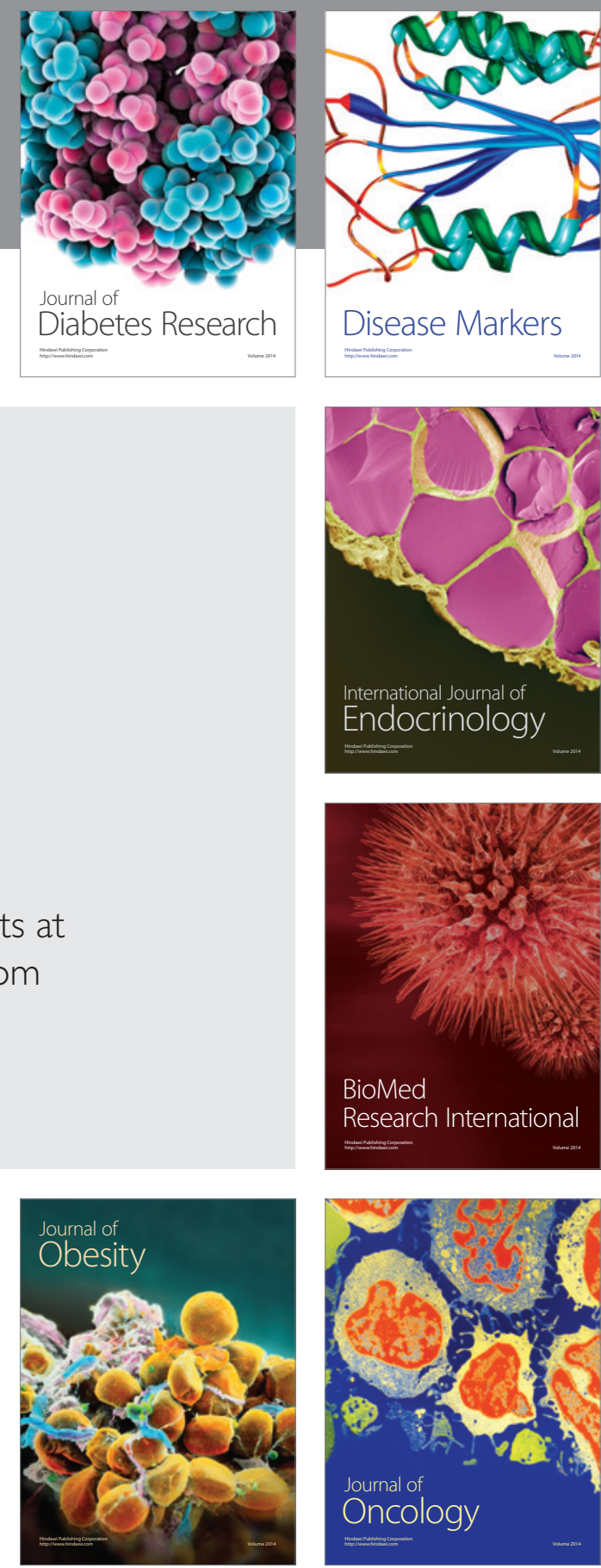

Disease Markers
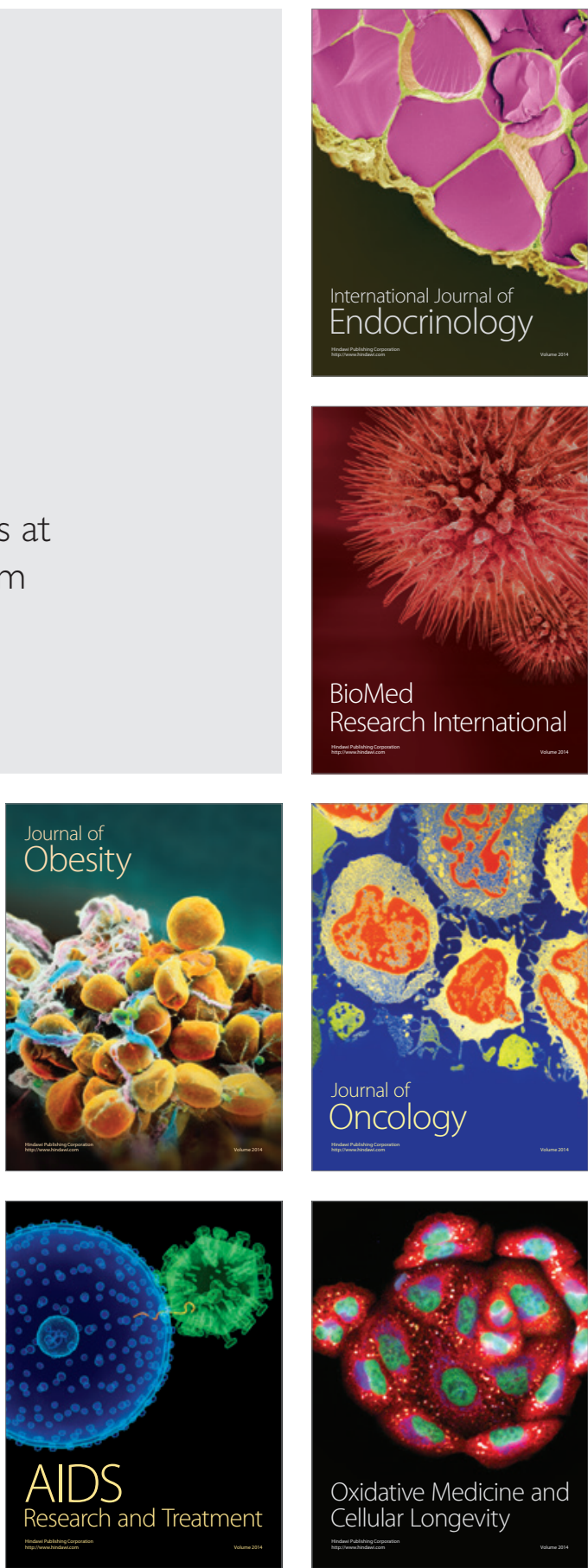